other teeth. It becomes a question of the view of the practitioner in every case. He should know when to extract and when to try to save. Dr. Rhein's practice is distinctly a family one and unless his patients are willing to abide by his decision he will not treat them. If they will not keep their mouths in a hygienically clean condition he does not waste his services. Patients are largely what dentists make them, and if the dentist can not train them properly we should not take charge of them.

\section{CHOLERA AND INFECTED WATERS.*}

CHARIES E. WOODRUFF, M.D.

Major and Surgeon U. S. Army.

PLATTSBURG BARRACKS, N. Y.

The experience gained by the American military surgeons during the Philippine cholera epidemic of 1902 and 1903 has enabled them to correct a few errors in the current theories as to the methods of the spread of this dreadfully fatal disease. From their knowledge of the biologic characters of the spirillum, they were forced into an investigation, first, of the manner in which the living germ was transported into uninfected territory, and, second, of the manner in which it was carried from patient to patient after it was planted in this new territory. The spirillum is a very frail organjsm, which leads practically a parasitic existence, for it soon perishes outside of the host. Experimentally, it has been determined that it is killed in five minutes by a temperature of $80 \mathrm{C}$., in two hours by drying, and more quickly still if dried in the sunlight. Hence, as an invariable rule, the living moist germ is carried from place to place either in an infected host or as a culture on moist foods.

It would, then, apparently be a simple matter to trace up the channel of infection, yet all the investigations were hampered by the remarkable difficulty of eliciting truthful information from the patient. It was first supposed that this was merely the characteristic of the Malay, who is notorious for the skill he possesses in evading the truth in his remarks on any topic when he imagines that the truth will react against him. It was found that in American sufferers also it was an extremely difficult matter to get them to confess where they had been eating or drinking. They may have been ashamed to confess that they had been so foolish as to violate sanitary regulations deliberately, but it was doubtless due, in great part if not entirely, to the interruption of the cerebral circulation, which made clear thinking impossible. It is not true that the patients are clear-headed in the throes of this disease, as so often reported.

Investigators, therefore, were compelled to resort to indirect evidence as to sources of infection and methods of spread. Almost invariably it was found that the first case in a new territory was a newcomer who had been infected elsewhere and who showed symptoms very shortly after his arrival. The short period of incubation made this evidence stand out with startling clearness. It is but a few hours after swallowing the germ that symptoms appear, and frequently patients were dead less than twenty-four hours after infection. The shortest case is said to have been ten hours from infection to the first symptoms. Hence, the traveler who brings the infection into a new neighborhood is usually desperately sick on arrival, and a patient is known to

* Read in the Section on Hyglene and Sanitary Science of the American Medical Association, at the Fifty-sixth Annual Session, July, 1905. have died fifteen minutes after he left a railroad car in which he had been travelling but an hour and a half.

We can safely say that practically the only way the infection is carried into a new territory is by infected travelers, for the other methods are so rare as to be mere curiosities. Yet foods are now and then the vehicle; for instance, in one town the first eighty cases were directly traced to a fiesta or banquet in which the food was supplied by a native caterer. He cooked the material in Manila, where it was undoubtedly infected, and then smuggled it into the distant town. It proved to be a splendid culture medium, so that when served it was no doubt swarming with spirilla. The cook himself died shortly after arrival and was probably infected from the same source which infected the food.

Curiously enough, it was probably by this rare method that cholera was introduced into the Philippine Islands from China, where the disease had been epidemic a long time. In the Orient, where intensive cultivation is carried to an extreme, human feces and urine are carefully collected and sold to the farmer as fertilizers. They are mixed with water and then sprinkled by watering pots on the leaves, so that a garden in China or Japan is a most foul smelling landscape to which distance lends enchantment. The result is evident. If there is cholera, trphoid, dysenterv or any similar infectious disease in the community, the bacteria are deposited in the cracks and crevices of the leaves of cabbages, celery, lettuce and such vegetables, and if thev are caten uncooked the disease is spread broadcast. Hence, in the Orient sensible people always eat their regetables cooked, but it is to be confessed that a stroll through a Japanese garden generally destroys all desire for oriental vegetables in any shape. Boiled feces may be harmless, but they are not an esthetic condiment.

For these reasons the quarantine authoritics in Manila forbade the importation of vegetables or any moist foods from cholera-infected ports, but one ship captain is said to have disobeyed orders and thrown Chinese vegetables overboard. They are reported to have been picked up on shore. What we certainly know is, that along this shore the first cases occurred in an epidemic which destroyed lives estimated variously at from 150,000 to a half million.

Though infected water is the chief means of spreading the disease locally from man to man in an infected territory, it is so rarely the means of carrying the disease into an uninfected area that it can be dismissed. I do not know of a single instance in the large area from which I reccived reports. Of course it is possible, as where boats take infected water into their tanks and spread the disease at the terminal port, but in that case there is sure to be an extensive epidemic on the boat, which will lead to prompt measures. This is due to the fact that the vibrio perishes in so short a time outside of the host. Experimentally, it has been shown to die in distilled water in 24 hours. in water of canals in one to four days-Koch savs in 36 hours. In sterilized milk it lives 10 dars; in unsterilized milk, 1 to 2 davs: in decoction of tea, 1/200, 8 days; in coffee, 2 hours; beer, 3 hours; acid wine, 1/4 hour.

The subject of the prevention of the spread of the infection into a clean territory is foreign to this paper. but it is appropriate to remark that, theoretically, it seems a very simple matter. If a quarantine can be organized on sufficiently rigid lines, so as to stop every traveler at the point of destination for five davs, every infected person could be discovered and his discharges 
disinfected until he recovers. Unfortunately, the spirilla remain in a convalescent many weeks or even months - they have been found seven weeks after all symptoms had disappeared. 'To keep him under control, then, is not as simple as it appears. Long after he is apparently well he may be a dangerous source of infection and nothing is safe except returning him to the territory whence he came. The quarantine itself is not always practicable, because it is easy to break through the lines, and this happened so often as to raise a suspicion that it was a useless bother and expense. Indeed, there are some who claim that as a land quarantine is sure to be inefficient and the infection spread in spite of our efforts, it is not wise to attempt any restrictive measures of the sort. This is rather fallacious reasoning and if we apply it to all human endeavors we would never attempt anything, for our efforts are rarely wholly successful. A quarantine does restrict the spread of cholera and to that extent it is an essential measure, for it lessens the number of new foci and restricts the number of deaths while we are waiting for the spirillum to lose its vitality, and this is a matter of only a few months. A marine quarantine is, of course, an entirely different matter and can be more efficient except in the matter of the retention of convalescents in the long period in which they can spread the infection.

It is certain that if on the discovery of the first cases in Manila that part of the city had been surrounded with guards, with orders to shoot any one escaping, and this severe quarantine had been continued for two months aftor the last case. the subsequent epidemic in the Philippines would have been prevented, but it is also evident that such measures would never be tolerated by public sentiment.

Commerce in dried merchandise need not be interrupted in the least, but moist foods from an infected territory must, of course, be wholly excluded. Particularly in the Orient is this necessarv, where, as before explained, the farmers are so filthy. The outery against quarantine invariably raised by commercial bodies interferes with its efficiency. Indeel, there is much to be said on the side of the merchants. Interference with trade is a very serious matter and may in the end cause poverty, privation, sickness and eventually lav the foundation for more deaths than the unrestricted spread of the cholera. Oriental communities are dreadfully overcrowded, and a large death rate is normal and necessary. Many must die, for the food supply is always short, and there is much to be said in favor of the present attitude of the British sanitarians in India who have in sheer hopelessness given up the task of preventing the spread of plague and such epidemics and are allowing the natives to kill themselves in the way which pleases them most. It seems brutal, but a careful investigation of the whole question generally convinces one that in dealing with Orientals laisse faire is more often the best motto than we are willing to: confess.

We now come to the most important side of choleraits spread from man to man, after the spirillum has been introduced into a new territory. Here we have very definite: data and we can lay down an invariable law, that without an infection of the water supply an extensive epidemic is impossible. Sporadic cases can occur in a city from infected foods and there may be little local outbursts here and there, as where a well has been infected, but unless the spirillum enters the water supplied to a great population, that population is com- paratively safe. The first thing done in Manila was to guard the water supply by military forces, and to this wise measure we can surely attribute the salvation of that city from a terrible disaster.

To be sure, Manila had some thousands of cases, a few no doubt due to wells here and there into which surface discharges drained, but the vast majority were due to the extremely filthy habits of the people in their food supplies. It is said that there are 50,000 people in that city who feed from the little restaurants which exist by hundreds and sell various kinds of soups, stews and other cooked foods. A prospective purchaser will run her hands into the mixture and if it does not suit her will pass on to the next merchant. If she has just helped to attend a cholera patient hidden away in her home, she inoculates the stew from her finger nails, and the mixture, being a fine culture medium, is soon swarming with spirilla. In this manner and from equally filthy household habits almost all of the Manila cases can be attributed. But they were mostly sporadic cases, here one and there one, probably only one member of a family. Now and then a single pupil in a boarding scohol would be stricken, and investigation would bring to light the fact that she had received food from the outside, say some confectionery or a salad. Flies undoubtedly carried the infection from patients' discharges to exposed food supplies and started cultures this way, but this was of minor importance in the presence of the far more numerous ways of carrying it on the hands of filthy natives.

In the provinces we no doubt had many similar cases, but the bad epidemics of towns were invariably due to infected waters. The streams in the Philippines are the life of the country, and houses are built on the banks or overhanging them, so that the stream acts as a water supply and sewer for every one. It naturally followed that, as soon as a case occurred, the discharges entered the water and there was a gencral epidemic in the population living further down stream. Where the stream was Jarge and there was a chance that one might drink some of the water without happening to take in a spirillum, the epidemic was not extensive, but where the stream was small and more crowded with spirilla the results were dreadful. In one town of this latter sort, the reports showed that over 25 per cent. of the inhabitants died within two or three weeks of the first case. In prior epidemics towns have been totally wiped out. Where there were many wells in addition to the stream, it was natural that some of them would escape infection and the users of that water escape. In one town, a famous spring supplied part of the people who were quite free of the disease which nearly decimated those using the river, and in those towns where the rich had well-protected cisterns for rain water these families were quite immune, excepting the sporadic cases infected elsewhere or from infected foods.

As before explained, the life of the spirillum in water is quite short. Reports from India show that infected wells and tanks are safe after three weeks, though we made no similar investigations in the Philippines. This fact gives the rational basis for the management of an epidemic. Of course, we must search for and destroy infected foods and prevent the sale of certain vegetables, like cabbage, which can harbor the germs, though many of the fruits and vegetables forbidden in the Manila epidemic were absolutely harmless. Mangoes, for instance, are not known to carry the infection. Bananas are probably safe, though there was a rumor at one time that the circulation of fluids in the plant was so rapid that bacilli 
could be carried up from the roots to the interior of the fruit, but it is safe to say that this is merely an illustration of the wild thoughts possible in the nervous tension of an epidemic.

The sterilization of the urine and feces of cholera patients is also of importance to prevent the bacilli being washed into any water supply. Deep burial or sterilization by heat are impracticable, and dependence must be placed on one of the methods of chemical sterilization useful in typhoid. Experimentally it is found that the cholera vibrios are killed in a few minutes by weak solutions of carbolic acid or corrosive sublimate, and by mineral acid, 1/10000, in a few seconds, but for excreta it is thought that milk of lime is the best, in the proportion of 1 part lime to 40 of water.

We must search for the sick, who are invariably concealed to escape quarantine, and we must isolate them to prevent them from fouling a water supply, and finally we must close up for several weeks all wells, tanks and cisterns known to be infected. The British sanitarians are wedded to the plan of disinfecting such cholera wells by adding 2 to 4 ounces of permanganate of potash, in which solution the spirilli promptly perish. The permanganate is said to destroy all dead organic matter and thus to sterilize the water by depriving the spirilli of food so that they die of starvation. To be effective there must be a faint pink tinge in the water the day after the permanganate is used. Foul wells which destroy the color at once should be pumped out, if possible, and cleaned. In the absence of permanganate, alum has the next best reputation, 4 to 8 ounces to a well, but it is a clarifier rather than a disinfectant and carries down the bacteria in the coagula it forms. Finally, lime, 40 to 50 pounds to a well has been used, but it is not a safe means, as we have no data that it destroys the spirilli, whereas the permanganate has been repeatedly known to stop an Indian epidemic in 3 days after it was added to every well in town. Of course, we run the risk of being accused of poisoning the wells, but we will be accused of this, anyhow, so it makes no difference.

The main reliance must be placed on boiled water for all purposes. The more completely we could enforce this measure the more successful was the management of an epidemic. It was quite possible to do this among soldiers, though they were apt to be careless until one or two in a company died through disobedience, but among the natives any such plan was hopelessly impractical, as a rule. They could not possibly understand why it was necessary to boil the water, and have been known to take boiled water into the house as a fetish of some sort and then drink what they pleased. Hence, among an Oriental population, prevention of spread of the infection is not possible, never has been and never will be. The white man must do the best he can for the natives, but look out for himself. The permanganate method is the best in such circumstances, but where the natives use an infected stream we are helpless, and the natives will die until the stream is cleaned out by a heavy storm. Time and time again in the Philippines have local epidemics ceased after a long heavy rain. It not only washes out the stream bed, but each native collects rainwater to save the trouble of carriage, and there is less use of the infected wells. On the other hand, we have seen local epidemics increase with the rains where the surface filth has thus been washed into wells which were previously sterile.

In regard to patent sterilizers, such as the ForbesWaterhouse, opinions are divided. This particular one is a complicated contrivance for boiling water and then to save fuel using this hot water to heat up the incoming stream. It hoils the water only a few seconds, but when carefully tested in a laboratory by skilled bacteriologists and intelligent men it delivers a steady stream of sterile water. In the field in actual use it is rarely successful, and I have repeatedly seen it used without heat at all. It is an extremely dangerous contrivance. The same condemnation must be given to all forms of portable filters. If they work easily, they merely act as clarifiers, as the spirilli easily pass through such large pores. When they are efficient they require considerable pressure which can only be obtained in permanent plants. The large permanent filters for public supplies have proved themselves efficient in filtering out cholera spirilli and need no further comment. The use of copper sulphate in minute doses or of copper foil is worthy of trial in wells and cisterns, for it may be of extreme value in the absence of the permanganate of potash.

If it is really true that a strip of copper foil 3 inches square in the water bottles will destroy intestinal parasites accidentally present, we have a most valuable discovery for tropical residents who can rarely depend on filthy natives. Indeed, it is suspected that here and there dysentery may have been due to unboiled infected water introduced by servants after they had stolen the water carefully sterilized by the master himself. The matter descrves the greatest attention in our laboratories. Acidulated water is no doubt efficacious if cholera is present, as the bacilli are destroyed by mineral acids, but it is unpleasant and will not be used except under compulsion, and the copper foil treatment is, therefore, an advantage if it proves to be germicidal. The use of acid in wells is apt to be resented by the natives much more than the permanganate and is probably less efficacious.

The extreme ease of personal prophylaxis is comforting at least. We lived for a year in the midst of this disease, sometimes seeing the natives die all around us, and in our houses, even in our kitchens, but if we were sure to drink only boiled water, or bottled fluids known to be sterile, and ate only cooked or canned foods from scalded dishes, there was not the slightest danger. The patient himself is as harmless as one with typhoid, and if his discharges are sterilized or buried he never transmits the disease to his nurses. Cases could be cared for in the main hospital or, indeed, anywhere, for isolation was wholly unnecessary. In the first excitement of the epidemic, rather hysterical orders were sent out to cremate the bodies of the dead and burn down their houses, but this was all unnecessary. The buried corpse was harmless, for the spirilli perished at once, One military campaign was made in Mindanao in territory where every stream was infected and the natives were dying in large numbers, but not a soldier was taken sick. If soldiers violated orders and drank from streams, the results were dreadful. In another campaign the commanding officer of one company and eight or ten of the men died from this carelessness.

The spirillum is such a pure parasite that it will soon die even in India, so that it is kept alive by constantly passing through new hosts in those regions where it is endemic. Outside of India it loses vitality in its excursions from host to host, so that in the course of time it is too enfeebled to infect a new host, and the disease dies out. In any one locality its virulence diminished in a few months or even weeks, so that toward the end of a local epidemic many patients recovered and the physicians in attendance built up fine reputations for curing their cases. My own experience and the supervision of very many different methods of treatment led me to the 
conclusion that there was nothing to be done for the patient, except make him as comfortable as possible. Morphin, hot applications and massage for the cramps, with strychnin and other heart stimulants later, were about all that could be done. Remedies by the stomach were only rejected, and saline injections, either intravenous or hypodermic, only passed into the intestines within a few minutes and drained off more blood serum. If the patient lived through the acute stage, he could be saved by skillful management of his food and stimulants, but the treatment of the acute stage is hopeless. It is purely a matter of the patient's resistance and the virulence of the particular culture of spirillum he has swallowed.

Hafflkine, in India, and Murata, in Japan, have apparently produced a certain degree of immunity by injecting the killed spirilli, and Strong, in Manila, has encouraging results with the fluid from which the killed spirilli have been filtered. Strong's filtrate causes a serum to form in man and animals which has high bactericidal and agglutinative power, though but slight antitoxic power. Work along these lines gives our only hope of future success.

Our main reliance, then, in cholera epidemics outside of India is to quarantine the infected area as rigidly as possible, protect water supplies, close up those known to be infected, use permanganate in the wells and cisterns, remove the sick to where they will be harmless, try to get the natives to use boiled water, prevent the sale and exposure of foods which are good culture media, and patiently wait until the spirilli have lost their virulence.

The above paper contains the conclusions to which we came as a result of the personal management of a severe and widespread epidemic, and it is also based on several score reports which came into my hands as chief surgeon of two of the brigades in the Philippines. As it would be meaningless and a waste of time to quote names, places, dates and statistics, these have been omitted, but it may be remarked that the official reports themselves are on file. It was requested that this paper would also include an account of the Spirillum cholerce asiatica, but we have discovered nothing new about this organism which is not already in the text-books.

We can conclude that we need never be afraid of a cholera epidemic in America, as sufficient is known to prevent it if we will not interfere with the sanitarians. One more Oriental plague has been removed from the list which has been the dread of the Occident, and once again we have a lesson that the people for their own protection had better give more authority to the sanitarians.

\section{DISCUSSION.}

Dr. Denstow Lewis, Chicago. stated that his experience with cholera is necessarily rery limited, being confined to observations in Europe in 1892, at which time he visited the principal European cities as a special commissioner from the Health Department of Chicago and from the Illinois State Roard of Health. Cholera broke out at Hamburg at that time and there were cases in Paris and a few in London. In Great Britain, the matter became of very serious importance on account of the isolated condition of that country, and Dr. Thorn-Thorn, now deceased, and Dr. Shirley Murphy of the health denartment of Jondon were up in arms against the entrance of cholera into England. Great excitement prevailed, and fear was expressed, not only that the cholera might spread, but that commerce would be interfered with. Dr. Jewis noted at that time the great value of having an effective sanitary organization throughout a country. In place of quarantining the ships, which would have interfered most seriously with commerce, it was possible in discharging the pasaengers to have each one under surveillance. so that no matter to what little town in England, Ireland or Scotland he should go, there would be a health officer there who would keep track of him and isolate him in case he showed any suspicious symptoms. Dr. Lewis said that it would be well in this country if our sanitary measures could be centralized to some extent, so that such a system of surveillance in case of necessity might be possible. It is easily seen what very great value this system has under these conditions. Dr. Lewis recalled a conversation he once had with Commander Lucien Young, in which the latter informed him that when his ship was in an infected harbor, the exceptional health of his men was remarked on. The sailors of other ships became ill, and many of them died, but his sailors were well. He attributed this freedom from disease to the use of alcohol, which he recommended on that occasion, and Dr. Lewis asked Dr. Woodruff's opinion regarding this matter, because, if alcohol under these conditions is of value, it is an important fact for physicians to know, for the lives of many of our sailors may depend on their knowledge.

DR. WOODRUFF said that with regard to quarantine at the port of entry, the British solution is the proper one for them. The existence of Great Britain depends on its trade, and any interruption of it, even for a short time, would be fatal. Twothirds of the people get their food from America, and at times there is on hand, so it is said, only three or four weeks' supply, so that they would really suffer from want of food in case of an interruption of their traffic for more than that time. That is the reason why war between Britain and America is utterly impossible; the British would not permit it. Consequently, they must have some means of following up cases and of preventing interruption of trade, and their splendidly organized sanitary service allows them to do that; but there is no other place in the world that Dr. Woodruff knows of where it can be done. All other places would have to keep a ship under surveillance. If there were any sick, they would be isolated, but the others could not be turned loose until it was certain they were not infected. With regard to alcohol, he said that the evidence is conclusive that any irritation of the stomach from alcohol permits the bacillus to get through into the intestine. It seems as though a person on a spree who drinks infected water is very apt to have cholera; Dr. Voodruff has seen that occur a number of times among soldiers. The stomach is undoubtedly able to dispose of an enormous number of spirilli, and in an epidemic people must be drinking spirilli all the time, but as they are killed in a few minutes in any acid solution, even one to ten thousand, the stomach juices in good health will destroy them. A man is safe unless he drinks an exceedingly large number of the germs; but if a soldier is allowed to go on a spree or to acquire in other ways an acute gastritis, it alters the tone of the stomach and probably lowers the acidity of the juices. Dr. Woodruff found many cases of soldiers dying shortly after drinking large quantities of alcohol. There is no evidence that small quantities of alcohol do any harm, but he does not think that alcohol is beneficial except in the case of acid wines. The spirilli will not live on the cut surface of a lemon, for instance, and acid drinks of all kinds are beneficial. The majority of physicians agree that it is better not to be a total abstainer in the tropics, but they are not willing to go on record, because it is so revolutionary. The very foundation of our faith in tropical hygiene is total abstinence, but Dr. Woodruff is convinced from the statistics that he has gathered that a. little stimulant with lunch and dinner, but at no other time, is a very good thing, though excessive drinking is exceedingly bad.

A Voice from the Tombs Warning Against Quacks.-There is said to be a monument in the graveyard at Hameln, in Germanv. over the graves of two children who died in 1792, which bears the following inscription. It states that the rhildren were sent to death "by a charlatan's hand-a warning to the entire land. Trust vour life only in the hands of a sure physician: if you die then you will at least have done rour duty."

Wir sind durch eines Pfuschers Hand zu früh hierher geschicket. 7ar Warnung fír das ganze Land und den. der dies erblicket. Sein I eben trave jedermann nur sich're Aerzte Hinden an: gethan. 